SUPPORTING INFORMATION

\title{
Virtual Screening Directly Identifies New Fragment-Sized Inhibitors of Carboxylesterase Notum with Nanomolar Activity
}

David Steadman, ${ }^{1}$ Benjamin N. Atkinson, ${ }^{1}$ Yuguang Zhao, ${ }^{2}$ Nicky J. Willis,${ }^{1}$ Sarah Frew, ${ }^{1}$ Amy Monaghan, ${ }^{1}$ Chandni Patel, ${ }^{1}$ Emma Armstrong, ${ }^{1}$ Kathryn Costelloe, ${ }^{1}$ Lorenza Magno, ${ }^{1}$ Magda Bictash, ${ }^{1}$ E. Yvonne Jones, ${ }^{2}$ Paul V. Fish, ${ }^{1, *}$ Fredrik Svensson ${ }^{1, *}$

1 Alzheimer's Research UK UCL Drug Discovery Institute, University College London, The Cruciform Building, Gower Street, London, WC1E 6BT, U.K.

2 Division of Structural Biology, Wellcome Centre for Human Genetics, University of Oxford, The Henry Wellcome Building for Genomic Medicine, Roosevelt Drive, Oxford, OX3 7BN, U.K.

*p.fish@ucl.ac.uk; *f.svensson@ucl.ac.uk 
Table of contents:

Page S3 Figure S1. Scatter plot of virtual screen single point screening results

Page S4 Figure S2. Structures of VS hits with a Notum (OPTS) IC $C_{50}<500 \mathrm{nM}$

Page S7 Figure S3. Residue numbers for human Notum active site

Page S8 Figure S4. Docking poses of E- and Z-oxazolones

Page S9 Figure S5. Correlation plot of Notum TCF/LEF vs OPTS screening data

Page S10 ADME protocols and data. (Tables S1-S8)

Page S14 Mouse Pharmacokinetic studies. (Tables S9 \& S10, Figure S6)

Page S16 Table S11. Data for additional oxazolones

Page S17 Table S12. X-ray structure determination: data collection and refinement statistics

Page S18 Figure S7. Notum pocket electrostatics

Page S19 Figure S8. Ligand electron-density maps

Page S21 Supplementary Experimental Section

Page S23 LCMS traces for $4 d, 4 f, 4 p$, and $4 y$. (Figures S9-S12)

Page S25 Notum OPTS and TCF/LEF screening data curves for 4d. (Figures S13-S16) 
Figure S1: Scatter plot of Notum screen single point screening results vs cLogD

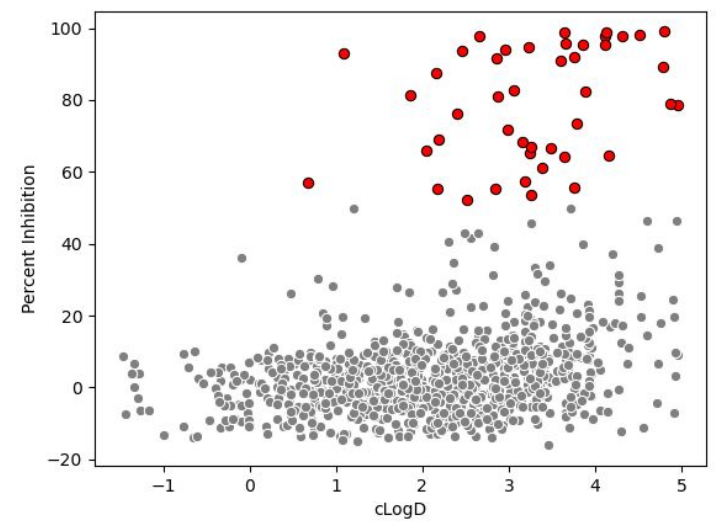

Figure S1. Scatter plot of Notum screen single point screening results $(1 \mu \mathrm{M})$ vs cLogD. All 952 purchased virtual hit compounds (grey). Experimentally validate hits (>50\% inhibition) (red). Percent inhibition is the average across two repeats. 
Figure S2: $\quad$ Structures of VS hits with a Notum (OPTS) IC $\mathrm{I}_{50}<500 \mathrm{nM}$<smiles>Cc1ccc(Sc2ccc3n[nH]c(=O)n3n2)cc1</smiles><smiles>Cc1ccc(-c2nn3c(=O)c(C)nnc3s2)cc1C</smiles>

C201-2006

D727-0293<smiles>Cc1ccccc1OCc1nn2c(=O)c(C)nnc2s1</smiles><smiles>O=C1OC(c2cccc(Cl)c2Cl)=N/C1=C/c1ccco1</smiles>

D727-0315

K088-1498

$\left.\left\langle\left.\right|^{2}\right\rangle^{\mathrm{Cl}}\right\rangle$<smiles>Cc1ccc(/C=C2/N=C(c3cccc(Cl)c3Cl)OC2=O)o1</smiles>

K088-1472

K088-1471<smiles>COc1ccc(/C=C2/N=C(c3cccc(Cl)c3Cl)OC2=O)c(OC)c1</smiles><smiles>O=C1OC(/C=C/c2ccccc2)=N/C1=C/c1ccco1</smiles>

K088-1456

K088-1164<smiles>Cc1ccc(C2=N/C(=C/c3ccccc3)C(=O)O2)cc1C</smiles><smiles>Cc1ccc(C2=N/C(=C/c3cccs3)C(=O)O2)cc1C</smiles>

2165-0859

2165-0836<smiles>Cc1ccc(/C=C2/N=C(c3ccc(C)c(C)c3)OC2=O)o1</smiles><smiles>O=C1OC(c2ccc(Cl)cc2Cl)=N/C1=C/c1ccco1</smiles>

2165-0835

1309-1753

S4 


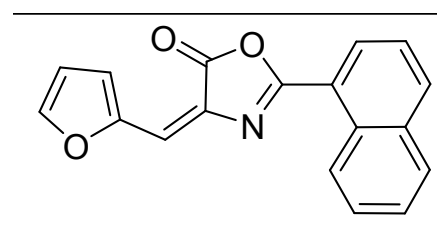

K076-1496

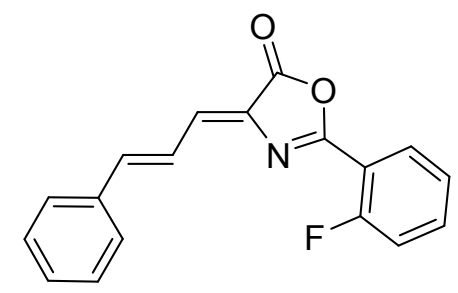

0878-7172<smiles>CC(=O)c1ccc2c(c1)c1ccccc1n2C(C)C</smiles>

2676-0013<smiles>CC(=O)c1ccc2c(c1)c1ccccc1n2C</smiles>

6042-0071<smiles>Cc1oc2cc3oc(=O)cc(C)c3cc2c1C</smiles>

D143-0017

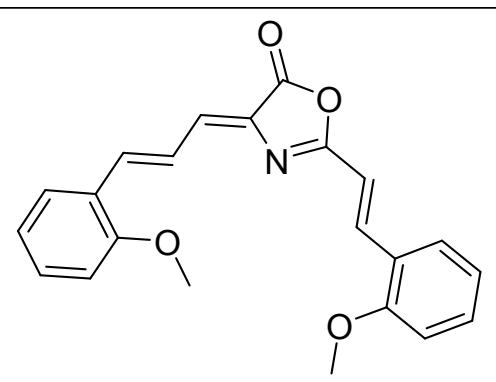

K088-3036

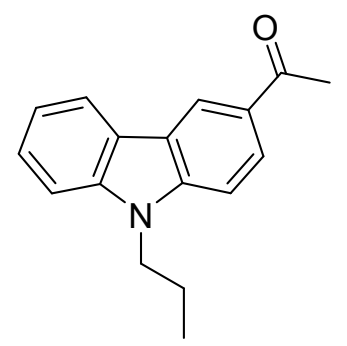

6042-0074

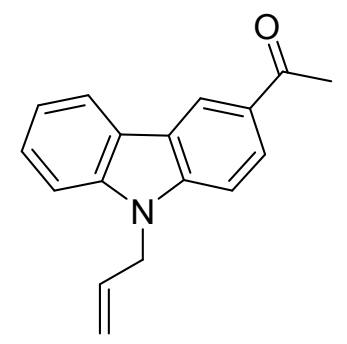

6042-0050

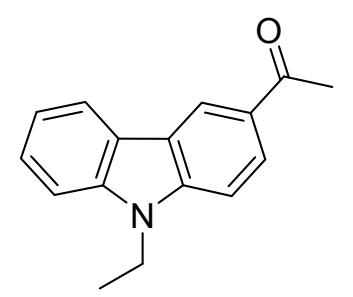

8018-7956

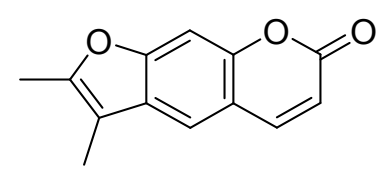

D143-0002 


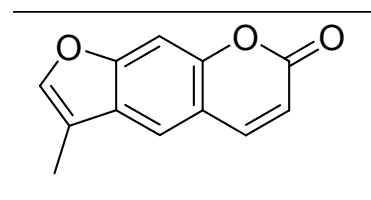

Y040-0156<smiles>CN1C(=O)N(C)c2cccc3cccc1c23</smiles>

4205-0089<smiles>COc1cc(C)c(/C=C/C(C)=O)c(C)c1C</smiles>

0530-0005<smiles>COC(=O)CCC(=O)N1CCc2ccccc21</smiles>

2663-0001<smiles>CN1/C(=C/C(=O)NC(=O)C(F)(F)F)C(C)(C)c2ccccc21</smiles><smiles>Cc1cc(=O)oc2cc3occ(C(C)(C)C)c3cc12</smiles>

D143-0018<smiles>CC(=O)c1ccc(N2CCCC[C@H]2C)c(F)c1</smiles>

3563-0128<smiles>O=C(CSc1ncnc2c1sc1cccc(F)c12)N1CCCC1</smiles>

F718-0521<smiles>CCOC(=O)CNC(=O)c1sc2cc(C)ccc2c1Cl</smiles>

Y200-3266

\section{8-1209}

Figure S2. Structures of VS hits with a Notum (OPTS) IC $C_{50}<500 \mathrm{nM}$. Supplier (ChemDiv) references given below each compound. 
Figure S3: $\quad$ Residue numbers for human Notum active site

A

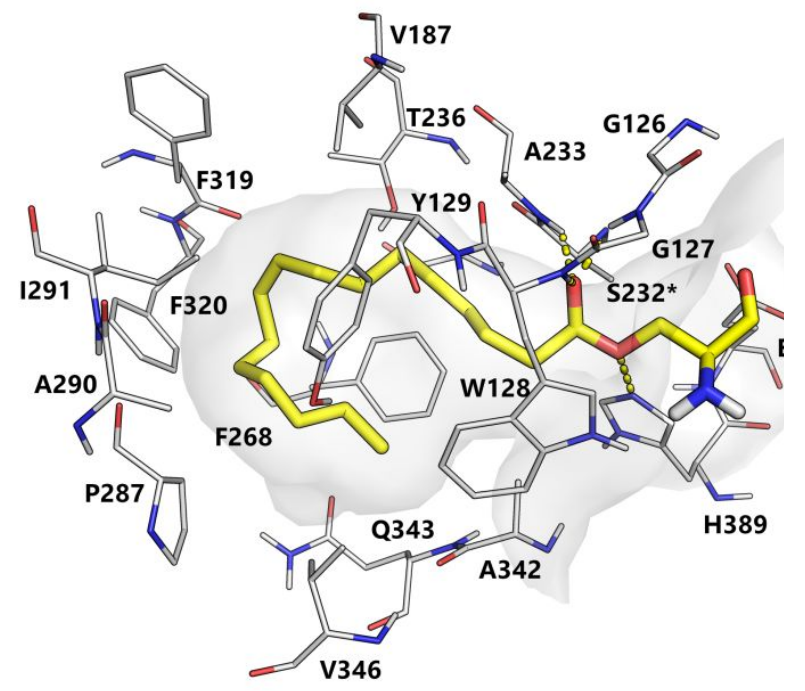

B

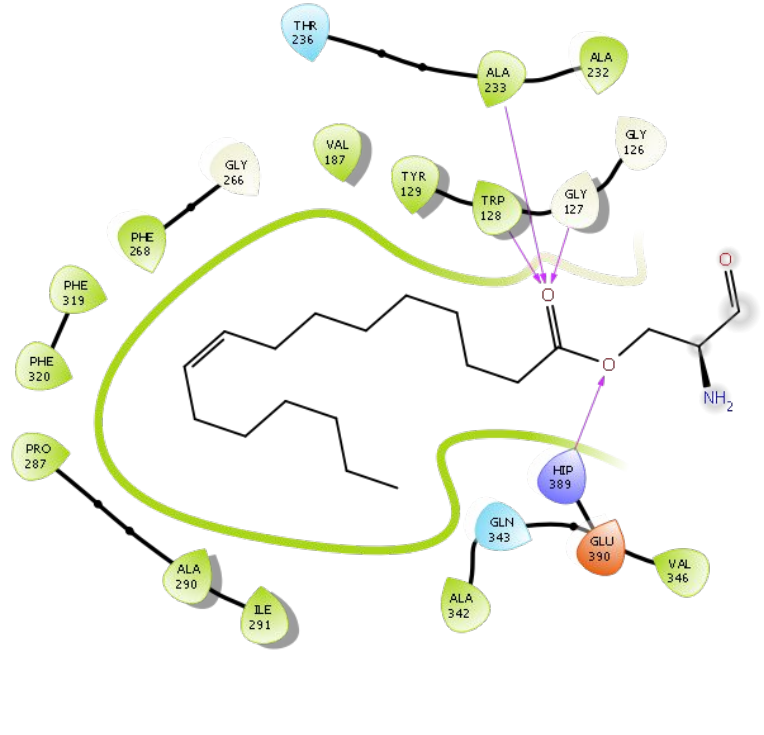

C

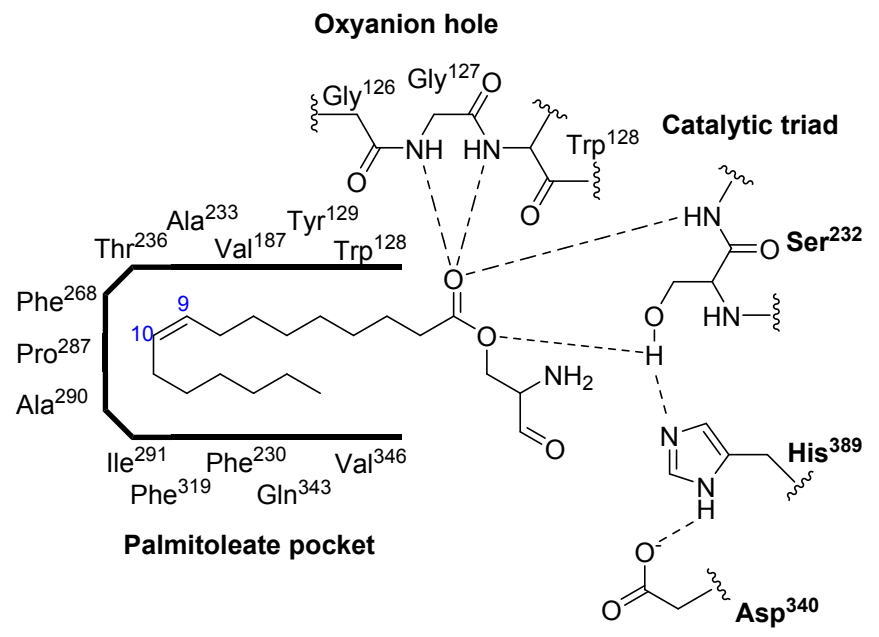

Figure S3 (A and B) PDB 4UZQ showing residue numbers for human Notum active site. Note that the catalytic serine 232 is mutated to alanine in this structure. (C) Two-dimensional cartoon of binding interactions. The Gly ${ }^{127}-\operatorname{Trp}^{128}$ amide participates in formation of the oxyanion hole in addition to the canonical Ser ${ }^{232}-\mathrm{Ala}^{233}$ and Gly ${ }^{126}$-Gly ${ }^{127}$ amides. Catalytic triad $\left(\mathrm{Ser}^{232}\right.$, His $\left.^{389}, \mathrm{Asp}^{340}\right)$ in bold. 
Figure S4: Docking poses of E- and Z-oxazolones

A

B
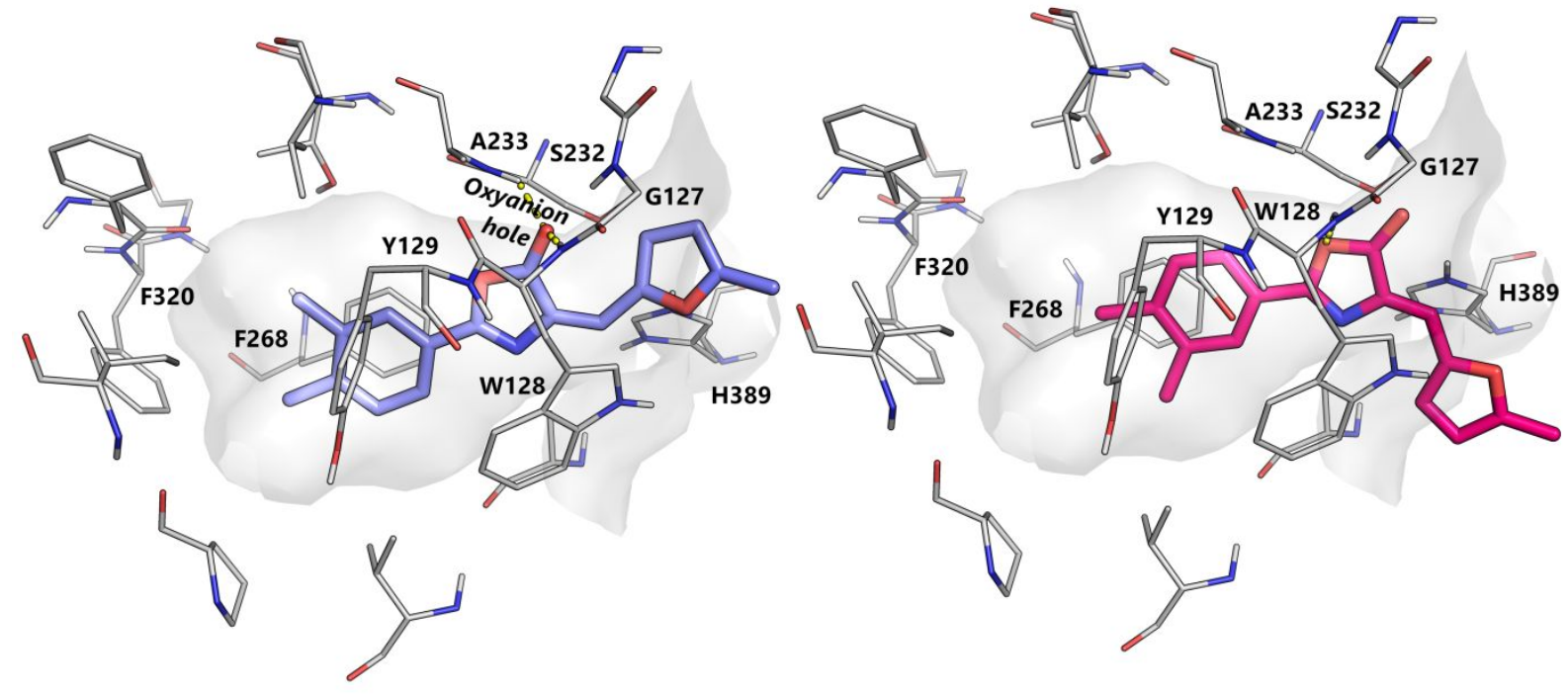

C

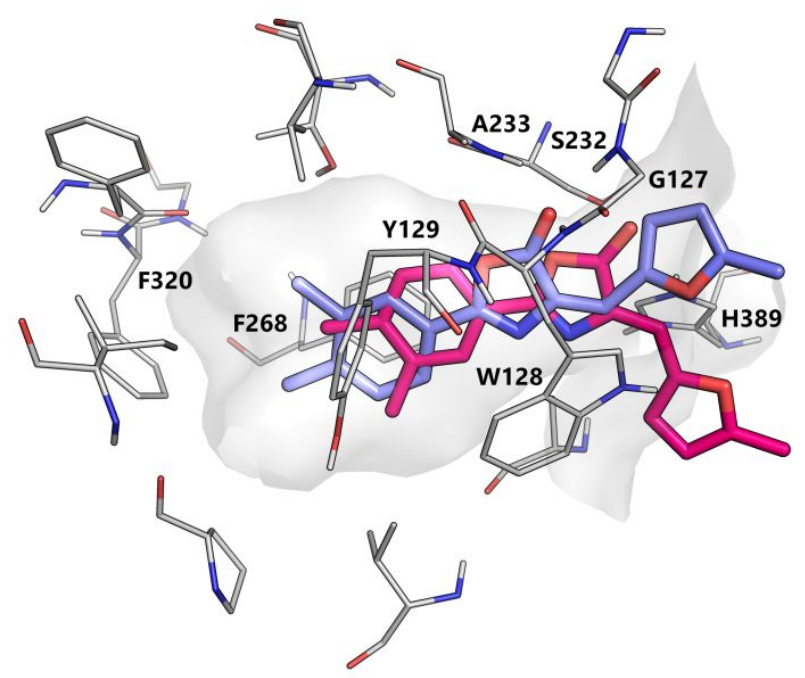

Figure S4. Docking poses of oxazolones (using 6T2K). (A) Original E-isomer 1f (Glide docking score -9.4). (B) Synthesized Z-isomer 1k (Glide docking score -6.5). (C) Overlay of $\mathbf{1 f}$ (purple) and $\mathbf{1 k}$ (pink). The preference for the $E$-isomer could be rationalized by the formation of a hydrogen bond between the oxazolone carbonyl oxygen and the oxyanion hole of the Notum active-site, which seemed optimal in the docking for the $E$-isomer. 
Figure S5. Correlation plot of Notum TCF/LEF vs OPTS screening data.

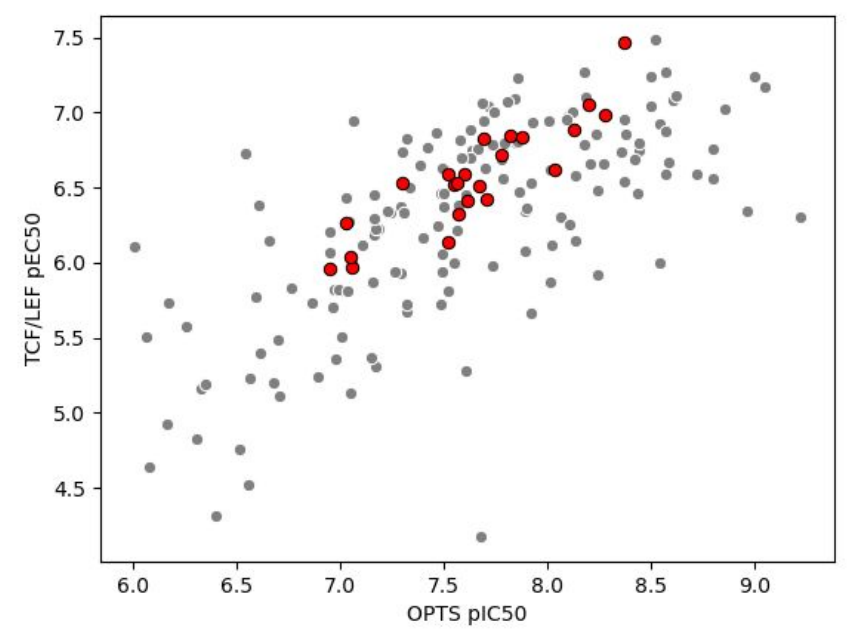

Figure S5. Correlation plot Notum TCF/LEF $\left(\mathrm{pEC}_{50}\right)$ vs OPTS $\left(\mathrm{plC}_{50}\right)$ screening data. Historical data (grey), triazolopyradizinones 4 (this work) (red). 


\section{ADME protocols and data}

ADME studies reported in this work were independently performed by GVK Biosciences (Hyderabad, India) or WuXi AppTec (China).

GVK Biosciences: https://www.gvkbio.com/discovery-services/biology-services/dmpk-services/

WuXi AppTec: https://labtesting.wuxiapptec.com/dmpk-services/in-vitro-adme/

\section{A. Aqueous solubility at $\mathrm{pH} \mathbf{7 . 4}$}

Table S1. Protocol summary.

\begin{tabular}{|l|l|}
\hline Method & plON solubility \\
\hline Test compound concentration & $500 \mu \mathrm{M}$ \\
\hline Buffer & plON buffer, $\mathrm{pH} \mathrm{7.4}$ \\
\hline Incubation Time & $18 \mathrm{hrs}$ \\
\hline No of Replicates & Three \\
\hline End point & Amount of compound soluble \\
\hline Analysis & Spectrophotometer \\
\hline
\end{tabular}

Table S2. Results Aqueous solubility at pH 7.4.

\begin{tabular}{|c|c|c|c|}
\hline \multirow{2}{*}{ Compound } & \multicolumn{2}{|c|}{ Solubility at $\mathrm{pH} \mathbf{7 . 4}$} & \multirow{2}{*}{ Category } \\
\cline { 2 - 3 } & Avg. Sol $(\boldsymbol{\mu g} / \mathrm{mL})$ & SD & \\
\hline $\mathbf{1 k}$ & 0.31 & 0.02 & Low \\
\hline 4d & 31.88 & 2.21 & Moderate \\
\hline Albendazole & 0.65 & 0.14 & Low \\
\hline Flurbiprofen & 74.59 & 1.04 & High \\
\hline
\end{tabular}

\section{B. Stability in liver microsomes.}

Table S3. Protocol summary.

\begin{tabular}{|l|l|}
\hline Test System & Mouse Liver Microsomes \\
\hline Test compound concentration & $1 \mu \mathrm{M}$ \\
\hline Time Points & $0,5,10,30$ and 60 minutes \\
\hline No of Replicates & Two \\
\hline Final Protein Concentration & $1 \mathrm{mg} / \mathrm{mL}$ \\
\hline Final NADPH Concentration & $1 \mathrm{mM}$ \\
\hline Potassium Phosphate Buffer $\mathrm{pH} 7.4$ & $100 \mathrm{mM}$ \\
\hline Final DMSO Concentration & $<0.1 \%$ \\
\hline Deliverables & $\begin{array}{l}\% \text { Remaining of test compound, } \\
\text { Half life, } \mathrm{CL}_{\text {int }}\end{array}$ \\
\hline Bioanalysis & LC-MS/MS \\
\hline Microsomes Lot no & MS048-B \\
\hline
\end{tabular}


Table S4. Results Stability in liver microsomes.

\begin{tabular}{|c|c|c|c|c|c|}
\hline Compound & $\begin{array}{c}\text { Half life } \\
\text { (min) }\end{array}$ & $\begin{array}{c}\text { \% Rem } \\
\mathbf{6} \mathbf{6 0} \mathbf{~ m i n}\end{array}$ & $\begin{array}{c}\text { CL int protein } \\
\mathbf{( \mu L / m i n / m g} \\
\text { protein) }\end{array}$ & $\begin{array}{c}\text { CL in vivo } \\
\text { (mL/min/kg } \\
\text { BW)-Well } \\
\text { stirred model }\end{array}$ & $\begin{array}{c}\text { \%QH } \\
\text { (Well stirred } \\
\text { model) }\end{array}$ \\
\hline $\mathbf{1 k}$ & 365.96 & 83.96 & 1.91 & 4.45 & 4.94 \\
\hline $\mathbf{4 d}$ & 51.13 & 43.03 & 13.57 & 24.26 & 26.96 \\
\hline Verapamil & 1.62 & 0.42 & 427.38 & 82.87 & 92.08 \\
\hline
\end{tabular}

\begin{tabular}{|c|c|}
\hline Classification criteria & $\% \mathbf{Q H}$ \\
\hline Low Clearance & $<30$ \\
\hline Moderate Clearance & $30-70$ \\
\hline High Clearance & $>70$ \\
\hline
\end{tabular}

\section{Permeability using MDCKII-MDR1 cell monolayer}

Table S5. Protocol summary.

\begin{tabular}{|l|l|}
\hline Cell origin & Solvo Biotechnology \\
\hline Test System & MDR1 MDCKII cells monolayer in 96 well format \\
\hline Passage number & 23 \\
\hline Test plate & $\begin{array}{l}\text { Poly carbonate high pore density from Millipore } \\
\text { with } 0.4 \mu \mathrm{m} \text { pore size, 0.11 } \mathrm{cm}^{2} \text { active membrane } \\
\text { area }\end{array}$ \\
\hline Test compound concentration & $10 \mu \mathrm{M}$ \\
\hline QC Compound concentration & $10 \mu \mathrm{M}$ \\
\hline $\begin{array}{l}\text { Bidirectonal assay (A-B \& B-A) time } \\
\text { points }\end{array}$ & 0 and 120 minutes \\
\hline Receiver wells & HBSS Buffer \\
\hline Replicates & Two \\
\hline End Point & Apparent permeability (Papp) and Efflux Ratio \\
\hline Bioanalysis & LC-MS/MS \\
\hline QC Compounds & $\begin{array}{l}\text { Propranolol (High Permeable), Atenelol (Low } \\
\text { Permeable) and Digoxin (Pgp Substrate) }\end{array}$ \\
\hline Assay Type & Bi-directional (A-B and B-A) \\
\hline
\end{tabular}


Table S6. Results permeability using MDCKII-MDR1 cell monolayer.

\begin{tabular}{|c|c|c|c|c|c|}
\hline \multirow{2}{*}{ Compound } & \multicolumn{5}{|c|}{ Average Values } \\
\hline & $\begin{array}{l}\text { Apical to Basal } \\
\text { Papp }\left(10^{-6} \mathrm{~cm} / \mathrm{s}\right)\end{array}$ & $\begin{array}{l}\text { Basal to Apical } \\
\text { Papp }\left(10^{-6} \mathrm{~cm} / \mathrm{s}\right)\end{array}$ & Efflux Ratio & $\begin{array}{l}\text { A to B \% } \\
\text { Recovery }\end{array}$ & $\begin{array}{l}\text { B to A \% } \\
\text { Recovery }\end{array}$ \\
\hline $1 \mathrm{k}$ & 0.00 & 0.00 & $\mathrm{NC}$ & 16.35 & 24.35 \\
\hline 4d & 51.61 & 42.66 & 0.83 & 104.40 & 106.17 \\
\hline Atenolol & 0.00 & 2.46 & $\mathrm{NC}$ & 114.50 & 86.38 \\
\hline
\end{tabular}

\begin{tabular}{|c|c|}
\hline $\begin{array}{c}\text { Result of permeability } \\
\text { Papp (10-6 } \mathbf{c m} / \mathbf{s})\end{array}$ & Classification \\
\hline$<1.5$ & Low permeable \\
\hline 1.5 to 10 & Medium permeable \\
\hline$>10$ & High permeable \\
\hline
\end{tabular}

\section{Mouse plasma protein binding.}

Protocol summary:

Determined by equilibrium dialysis. CD-1 mouse plasma from 20 male individuals (minimum). Beijing Vital River Laboratory Animal Technology Co., Ltd (\# 20190116-12).

Table S7. Results mouse plasma protein binding.

\begin{tabular}{|c|c|c|c|c|c|c|}
\hline Compound & $\begin{array}{c}\text { Test } \\
\text { Concentration } \\
(\mu \mathrm{M})\end{array}$ & $\begin{array}{l}\text { Species I } \\
\text { Matrix }\end{array}$ & $\%$ Unbound & $\begin{array}{c}\% \text { Unbound } \\
\text { SD }\end{array}$ & $\%$ Bound & $\%$ Recovery \\
\hline 4d & 2 & $\begin{array}{l}\text { CD-1 Mouse } \\
\text { Plasma }\end{array}$ & 1.12 & NA & 98.88 & 93.4 \\
\hline
\end{tabular}

\section{E. Acidic dissociation constant $\left(\mathrm{p} K_{\mathrm{a}}\right)$.}

Instrument:

Sirius T3Dt

Protocol summary:

a. $\quad \mathrm{p} K_{\mathrm{a}}$ determination by UV metric method (with co-solvent):

Pipetted $5 \mu \mathrm{L}$ of sample stock solution (10 mM in DMSO) and $25 \mu \mathrm{L}$ fast UV buffer into a sample vial, and $1.5 \mathrm{~mL}$ of $80 \% \mathrm{v} / \mathrm{v} \mathrm{MeOH}$ was added into the sample vial automatically. Pre-acidified the sample solution with $0.5 \mathrm{M} \mathrm{HCl}$ by the instrument automatically, and then titrated three times from low to high $\mathrm{pH}$.

Refined the data to get aqueous $\mathrm{p} K_{\mathrm{a}}$ value.

b. $\quad \mathrm{p} K_{\mathrm{a}}$ determination by $\mathrm{pH}$ metric method (with co-solvent):

About $1 \mathrm{mg}$ of sample was weighed into a sample vial. $1.50 \mathrm{~mL}$ of $80 \% \mathrm{v} / \mathrm{v} \mathrm{MeOH}$ was added into the vial automatically. The sample was solution pre-acidified with $0.5 \mathrm{M} \mathrm{HCl}$ by the instrument automatically, and then titrated three times from low to high $\mathrm{pH}$. Refined the data to get aqueous $\mathrm{p} K_{\mathrm{a}}$ value. 
Table S8. Results acidic dissociation constant $\left(\mathrm{p} K_{\mathrm{a}}\right)$.

\begin{tabular}{cccc}
\hline Compound & $\begin{array}{c}\mathrm{p} K_{\mathrm{a}} \\
\text { (UV metric) }\end{array}$ & $\begin{array}{c}\mathrm{p} K_{\mathrm{a}} \\
\text { (pH metric) }\end{array}$ & $\begin{array}{c}\text { Final } \mathrm{p} K_{\mathrm{a}} \\
\text { Result }\end{array}$ \\
\hline 4d & 7.97 & 7.93 & 7.95 \\
\hline
\end{tabular}

Final $\mathrm{p} K_{\mathrm{a}}$ was obtained by UV metric at $\mathrm{pH} 2-12$ and $\mathrm{pH}$ metric at 3-11 


\section{Mouse Pharmacokinetic studies}

In vivo mouse pharmacokinetic data was generated at Concept Life Sciences (Chapel-en-le-Frith, U.K.). Concept Life Sciences: https://www.conceptlifesciences.com/pharmaceutical/adme-dmpk/

Animal Testing Declaration: All in life phase studies were conducted in accordance with both a UK Home Office licence granted under the Animal (Scientific Procedures) Act 1986 and with a local Ethics Review process.

Table S9. Protocol summary.

\begin{tabular}{|l|l|}
\hline Species: & Mouse \\
Strain: & C57BL/6J \\
Dosing & Cassette \\
IV formulation: & $10 \%$ DMSO $/ 90 \%$ HPCD $(20 \% \mathrm{w} / \mathrm{v})$ \\
IV Dose $(\mathrm{mg} / \mathrm{kg})$ & 0.4 \\
Sampling Type: & Terminal \\
Matrix & Plasma \\
\hline
\end{tabular}

Table S10. Results mouse Pharmacokinetic studies.

\begin{tabular}{|c|c|c|c|c|}
\hline \multirow{2}{*}{ Intravenous } & \multicolumn{4}{|c|}{} \\
\cline { 2 - 5 } & \multicolumn{4}{|c|}{ Concentration (ng/mL) Mean n=3 animals* } \\
\cline { 2 - 5 } & $4 \mathrm{~d}$ & $4 \mathrm{f}$ & $4 \mathrm{p}$ & $4 \mathrm{y}$ \\
\hline 0.08 & 2299.4 & 980.9 & 956.3 & 958.6 \\
0.25 & 1777.7 & 306.7 & 242.0 & 352.2 \\
0.5 & 1469.1 & 74.8 & 39.2 & 116.3 \\
1 & 774.3 & 9.8 & 10.1 & 29.9 \\
2 & 276.6 & 5.9 & $<L L O Q$ & 13.8 \\
4 & 19.7 & $<L L O Q$ & $<L L O Q$ & 13.7 \\
8 & $<L L O Q$ & $<L L O Q$ & $<L L O Q$ & $<L L O$ \\
24 & $<L L O$ & $<L L O Q$ & $<L L O Q$ & $<L O Q$ \\
\hline LOQ $(\mathrm{ng} / \mathrm{mL})$ & 10 & 5 & 10 & 10 \\
\hline
\end{tabular}

*Exceptions for $\mathbf{4 d} 0.08 \mathrm{hr}$ ( $\mathrm{n}=1$ animal) as the rest $>$ ULOQ with $\mathbf{4 f} \mathbf{2} \mathrm{hr}(\mathrm{n}=1)$ as rest $<$ LLOQ.

In addition, $4 y 2 \mathrm{hr}$ ( $\mathrm{n}=2$ animals) and $4 \mathrm{hrs}$ ( $\mathrm{n}=1$ animal) and $4 \mathrm{p} 1 \mathrm{hr}$ ( $\mathrm{n}=1$ animal) as rest $<$ LLOQ. 


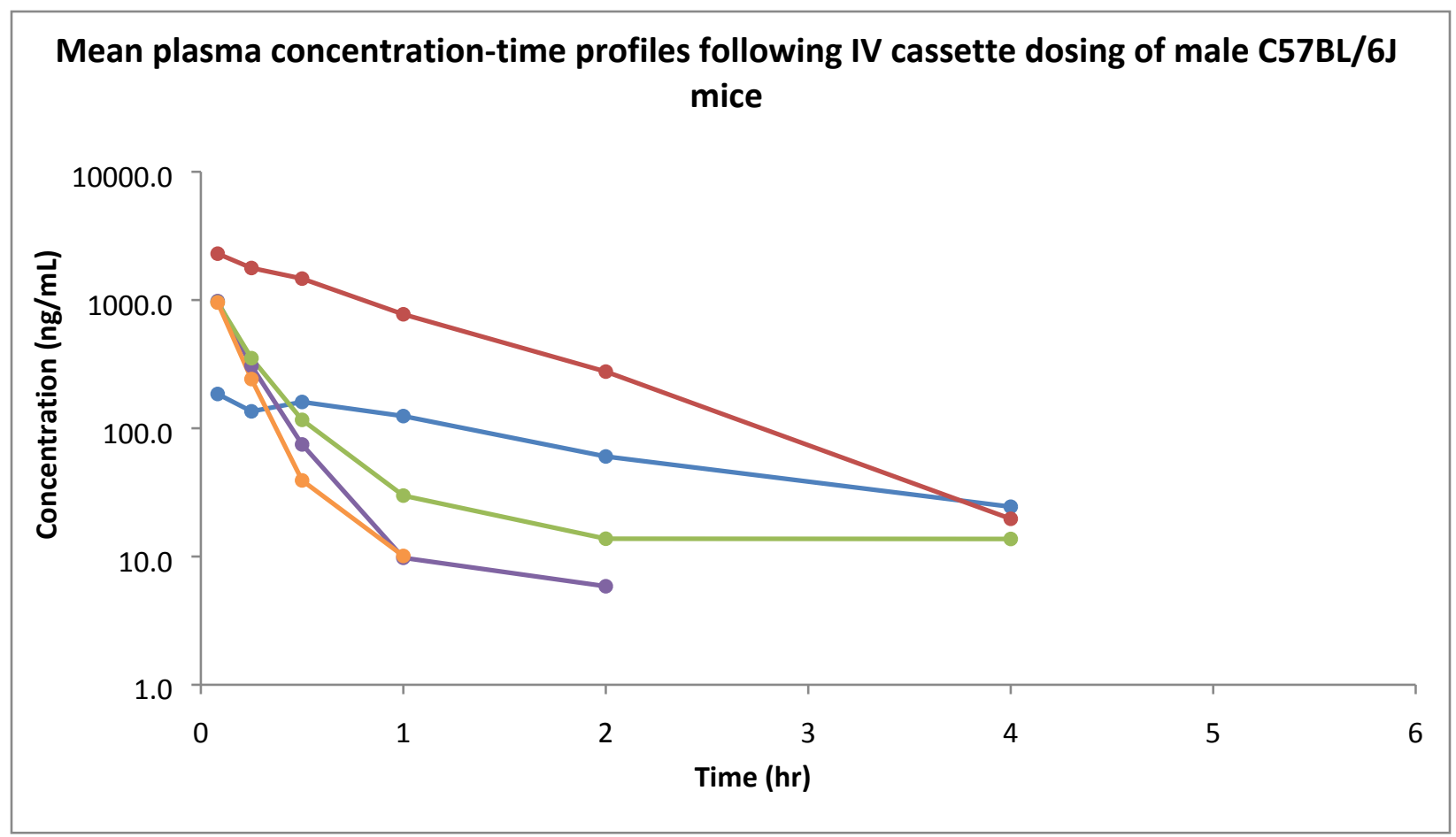

Figure S6. Mean plasma concentrations vs time profile for $\mathbf{4 d}$ (red), $\mathbf{4 f}$ (purple), $\mathbf{4 p}$ (orange), $\mathbf{4 y}$ (green) and control (blue) after intravenous administration to male C57BL/6J mice. 
Table S11. Data for additional oxazolones S1I-S10 ${ }^{\mathrm{a}, \mathrm{b}}$

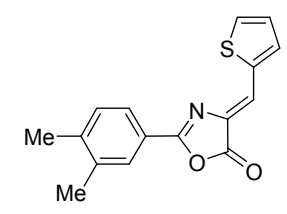

S1I

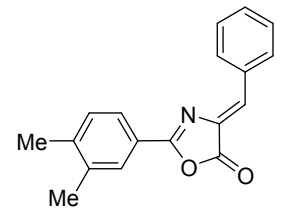

S1m

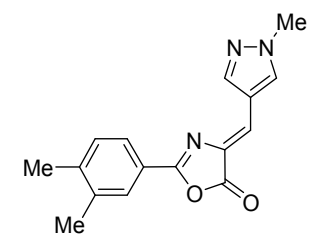

S1n

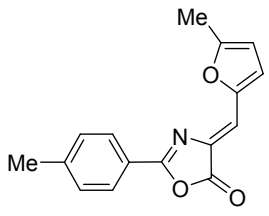

S10

\begin{tabular}{|c|c|c|c|c|}
\hline Compound & S1I & S1m & S1n & S10 \\
\hline Notum $\mathrm{IC}_{50}(\mathrm{nM})$ & 35 & 88 & 81 & 87 \\
\hline Notum $\mathrm{EC}_{50}(\mathrm{nM})$ & $>10,000$ & $>10,000$ & $>10,000$ & $>10,000$ \\
\hline $\operatorname{clog} \mathrm{P}$ & 4.3 & 4.6 & 2.8 & 4.2 \\
\hline Aq. solubility $(\mu \mathrm{g} / \mathrm{mL})$ & 0.09 & 0.28 & 3.6 & 0.29 \\
\hline MLM & & & & \\
\hline $\begin{array}{l}\mathrm{CL}_{\text {int }}(\mu \mathrm{L} / \mathrm{min} / \mathrm{mg} \text { protein }) \\
{\left[\mathrm{t}_{1 / 2}(\min )\right]}\end{array}$ & $\begin{array}{l}1.98 \\
{[360]}\end{array}$ & $\begin{array}{l}2.26 \\
{[320]}\end{array}$ & $\begin{array}{l}0.42 \\
{[2100]}\end{array}$ & $\begin{array}{l}0.42 \\
{[1800]}\end{array}$ \\
\hline $\begin{array}{l}\text { MDR1-MDCKII }{ }^{\mathrm{c}} \\
\mathrm{P}_{\mathrm{app}} \mathrm{AB} / \mathrm{BA}\left(\times 10^{-6} \mathrm{~cm} / \mathrm{s}\right)\end{array}$ & $0 / 0$ & $0 / 0$ & $0 / 0$ & $0 / 0$ \\
\hline
\end{tabular}

${ }^{a} \mathrm{IC}_{50}$ and $\mathrm{EC}_{50}$ values refer to the Notum OPTS and TCF/LEF assays respectively.

${ }^{b}$ All values are mean of $n=2-4$ experiments quoted to 2 s.f. Differences of $<2$-fold should not be considered as significant.

${ }^{c} A B$ and $B A \%$ recoveries were low. 
Table S12. X-ray structure determination: data collection and refinement statistics.

\begin{tabular}{|c|c|c|c|c|c|c|c|c|}
\hline Compound ID & $4 c$ & $4 d$ & $4 e$ & $4 f$ & $4 \mathrm{~g}$ & $4 p$ & $4 r$ & $4 y$ \\
\hline PDB ID code & 7B3X & 7B4X & 7B3G & 7B3I & 7B3P & 7B3H & 7B45 & 7B50 \\
\hline Ligand code & SUT & SWT & SSQ & STK & SUQ & SSW & SWQ & SXQ \\
\hline \multicolumn{9}{|l|}{ Data collection } \\
\hline $\begin{array}{l}\text { X-ray source } \\
\text { (Diamond) }\end{array}$ & 103 & 103 & 103 & 103 & 103 & 103 & 103 & 103 \\
\hline Wavelength (Å) & 0.9762 & 0.9762 & 0.9762 & 0.9762 & 0.9762 & 0.9762 & 0.9762 & 0.9762 \\
\hline Space group & $\mathrm{P} 2_{1} 2_{1} 2_{1}$ & $\mathrm{P} 2_{1} 2_{1} 2_{1}$ & $\mathrm{P} 2_{1} 2_{1} 2_{1}$ & $\mathrm{P} 22_{1} 2_{1} 2_{1}$ & $\mathrm{P} 2_{1} 2_{1} 2_{1}$ & $\mathrm{P} 2_{1} 2_{1} 2_{1}$ & $\mathrm{P} 2_{1} 2_{1} 2_{1}$ & $\mathrm{P} 22_{1} 2_{1} 2_{1}$ \\
\hline \multicolumn{9}{|l|}{ Cell dimensions } \\
\hline$a, b, c(\AA)$ & $\begin{array}{c}59.25,72.93 \\
79.41\end{array}$ & $\begin{array}{c}59.19 \\
72.99,77.73\end{array}$ & $\begin{array}{c}59.42,72.54 \\
78.06\end{array}$ & $\begin{array}{c}59.53 \\
72.46,78.11\end{array}$ & $\begin{array}{c}59.32,73.00 \\
77.86\end{array}$ & $\begin{array}{c}\text { 59.40, } 73.08 \\
78.58\end{array}$ & $\begin{array}{c}59.79,72.20 \\
78.14\end{array}$ & $\begin{array}{c}59.34,72.87 \\
77.90\end{array}$ \\
\hline$\alpha, \beta, \gamma\left(^{\circ}\right)$ & $90,90,90$ & $90,90,90$ & $90,90,90$ & $90,90,90$ & $90,90,90$ & $90,90,90$ & $90,90,90$ & $90,90,90$ \\
\hline Resolution $(\AA ̊)$ & $\begin{array}{l}53.25-1.34 \\
(1.36-1.34)\end{array}$ & $\begin{array}{l}53.21-1.24 \\
(1.26-1.24)\end{array}$ & $\begin{array}{c}53.1-1.28(1.30 \\
-1.28)\end{array}$ & $\begin{array}{c}53.1-1.34(1.36- \\
1.34)\end{array}$ & $\begin{array}{l}53.25-1.28 \\
(1.30-1.28)\end{array}$ & $\begin{array}{c}47.21-1.28 \\
(1.30-1.28)\end{array}$ & $\begin{array}{c}53.03-1.38 \\
(1.40-1.38)\end{array}$ & $\begin{array}{c}47.20-1.33 \\
(1.35-1.33)\end{array}$ \\
\hline $\begin{array}{l}\text { No. unique } \\
\text { reflections }\end{array}$ & 76494 (3756) & $95744(4548)$ & 87567 (4328) & $76523(3772)$ & 87713 (4329) & $87738(4351)$ & $70022(3388)$ & 78195 (3817) \\
\hline $\mathrm{I} / \sigma(\mathrm{I})$ & $18.6(1.0)$ & $10.2(1.0)$ & $15.5(1.1)$ & $18.2(1.0)$ & $21.8(1.3)$ & $16.0(1.2)$ & $18.3(1.2)$ & $11.8(1.0)$ \\
\hline CC $1 / 2$ & $1.0(0.63)$ & $1.000(0.739)$ & $1.0(0.67)$ & $1.00(0.666)$ & $1.0(0.81)$ & $1.0(0.74)$ & $1.0(0.67)$ & $1.00(0.73)$ \\
\hline Completeness (\%) & 100 (99.5) & 99.9(96.4) & 100 (99.9) & $100(99.3)$ & 100 (99.9) & 100(99.9) & $99.7(98.2)$ & 100(99.2) \\
\hline Redundancy & $26.2(24.5)$ & $25.5(24.3)$ & $13.0(12.6)$ & $39.1(35.9)$ & $26.1(25.5)$ & $13.0(12.7)$ & $13.2(12.6)$ & $26.1(23.5)$ \\
\hline \multicolumn{9}{|l|}{ Refinement } \\
\hline Rwork / Rfree & $0.198 / 0.203$ & $0.2024 / 0.2191$ & $0.202 / 0.215$ & $0.196 / 0.197$ & $0.188 / 0.199$ & $0.195 / 0.204$ & $0.190 / 0.194$ & $0.201 / 0.205$ \\
\hline $\begin{array}{c}\text { Average B-factors } \\
\left(\AA^{2}\right)\end{array}$ & 22 & 24 & 23 & 25 & 22 & 20 & 23 & 24 \\
\hline \multicolumn{9}{|l|}{ RMSD } \\
\hline Bond lengths $(\AA)$ & 0.006 & 0.005 & 0.004 & 0.007 & 0.008 & 0.007 & 0.007 & 0.007 \\
\hline Bond angles $\left({ }^{\circ}\right)$ & 0.95 & 1.09 & 1.41 & 1.5 & 1.06 & 1.07 & 1.03 & 0.98 \\
\hline
\end{tabular}

Values in parentheses are for highest-resolution shell 


\section{Figure S7. Notum pocket electrostatics}
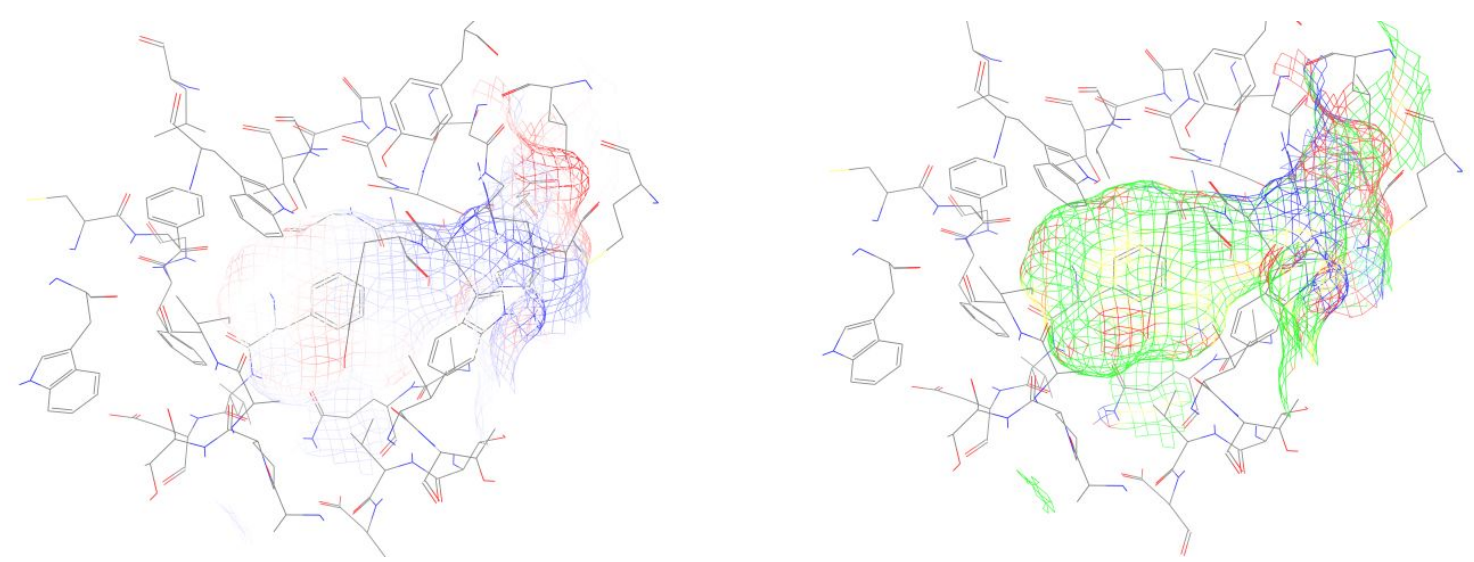

Figure S7. Notum binding pocket electrostatic potential (left) and partial charge (right), revealing a largely hydrophobic pocket and charges concentrated around the oxyanion hole. 
Figure S8. Ligand electron-density maps.

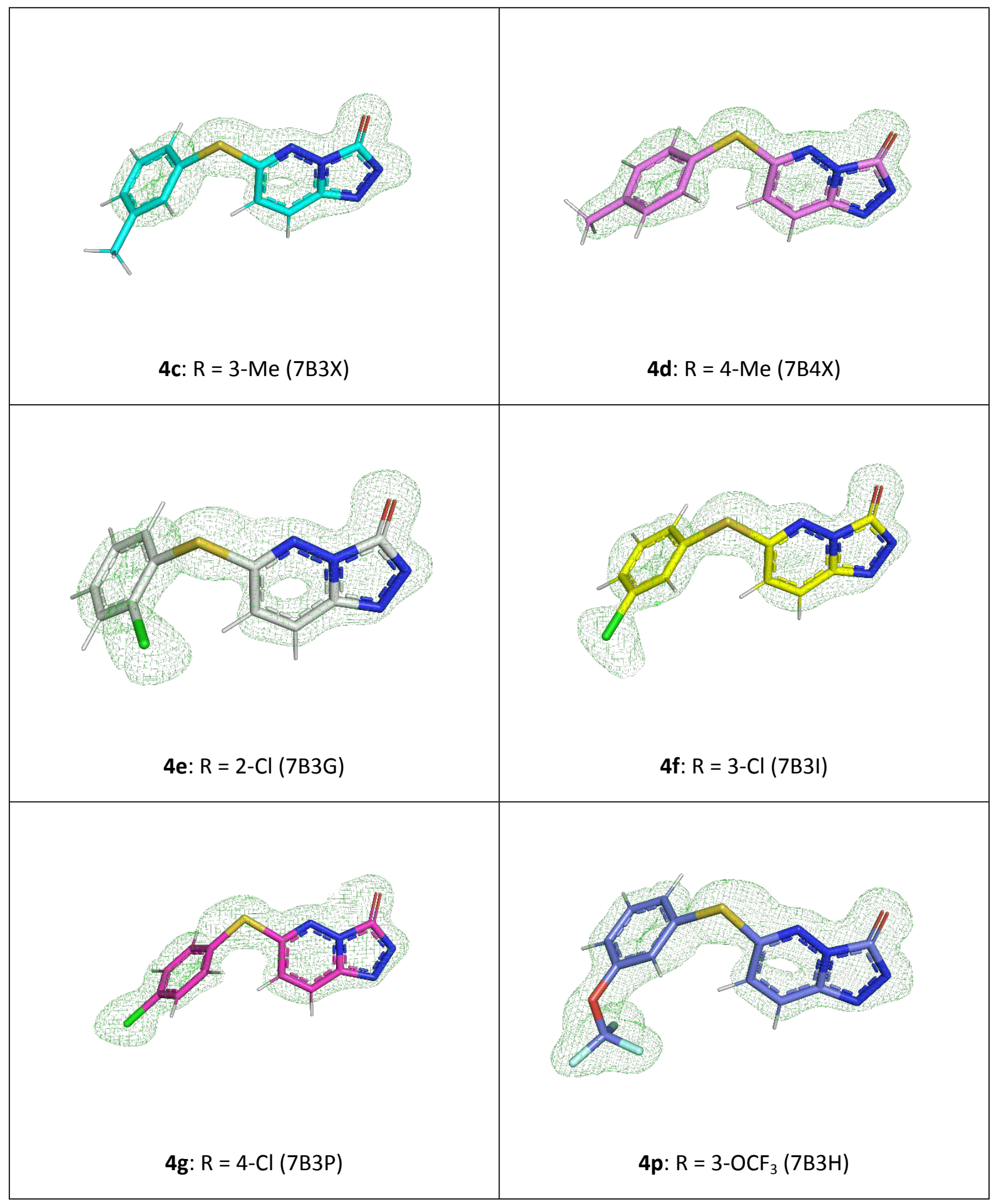




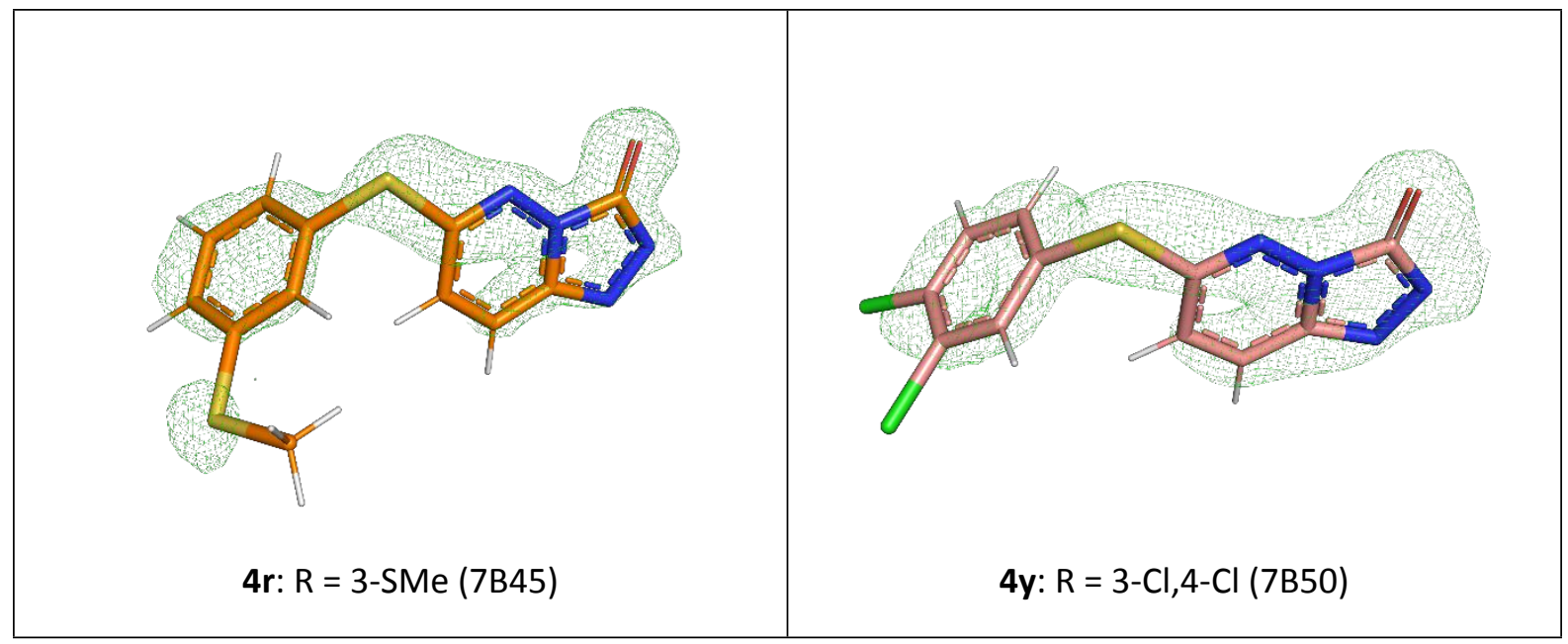

Figure S8. Ligand electron-density maps (green mesh $\left|F_{O}-F_{C}\right|$ omit map contoured at $3 \sigma$ ) for the presented crystal structures. Purity and identity of all compounds were verified prior to crystallography as described in the Experimental Section. 


\section{Supplementary Experimental Section}

The synthetic routes, General Information and General Methods are identical to the main Article.<smiles>[R]C(=O)NCC(=O)O</smiles>

5<smiles>[R]C=O</smiles>

6
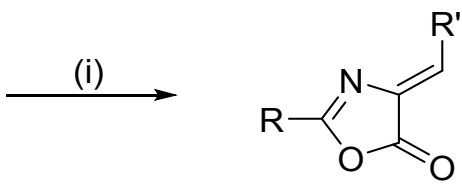

1

Scheme S1. Synthesis of (Z)-oxazol-5(4H)-ones (1). Reagents and conditions: (i) Formamidoacetic acid 5 (1.0 equiv.), aldehyde 6 (1.0 equiv.), $\mathrm{NaOAc}$ (1.0 equiv.), $\mathrm{Ac}_{2} \mathrm{O}, 140{ }^{\circ} \mathrm{C}, 2 \mathrm{~h}$.

Preparation of oxazol-5(4H)-ones 1 (General Method 1).

To a stirred solution of the aldehyde $6(0.56 \mathrm{mmol})$ in $\mathrm{Ac}_{2} \mathrm{O}(2.0 \mathrm{~mL})$ was added $\mathrm{NaOAc}(46 \mathrm{mg}, 0.56 \mathrm{mmol})$ and the formamidoacetic acid $5(0.56 \mathrm{mmol})$. The reaction was heated to $140{ }^{\circ} \mathrm{C}$ for $2 \mathrm{~h}$ and then allowed to cool to RT. The reaction was quenched with $\mathrm{H}_{2} \mathrm{O}$ and the product was extracted with $\mathrm{CH}_{2} \mathrm{Cl}_{2}$. Solvents were removed in vacuo and exchanged with DMSO. Products 1 were then purified by reverse phase flash silica chromatography (20-100\% $\left.\mathrm{MeCN}: \mathrm{H}_{2} \mathrm{O}, 0.1 \% \mathrm{NH}_{4} \mathrm{OH}\right)$ unless stated otherwise.

\section{(4Z)-2-(3,4-Dimethylphenyl)-4-(2-thienylmethylene)oxazol-5-one (S1I)}

Prepared following General Method 1 with 2-thiophenecarboxaldehyde (52 $\mu \mathrm{L}, 0.56 \mathrm{mmol})$ and 2-[(3,4dimethylphenyl)formamido]acetic acid (120 mg, $0.56 \mathrm{mmol})$. Isolated as a yellow solid (19 $\mathrm{mg}, 0.067$ $\mathrm{mmol}, 12 \%)$.

${ }^{1} \mathrm{H}$ NMR $(400 \mathrm{MHz}, \mathrm{CDCl} 3) \delta 7.95-7.86(\mathrm{~m}, 2 \mathrm{H}), 7.71(\mathrm{dt}, J=5.1,0.9 \mathrm{~Hz}, 1 \mathrm{H}), 7.65-7.59(\mathrm{~m}, 1 \mathrm{H}), 7.44(\mathrm{~s}$, 1H), $7.31-7.23(\mathrm{~m}, 1 \mathrm{H}$, under solvent peak), $7.16(\mathrm{dd}, J=5.1,3.8 \mathrm{~Hz}, 1 \mathrm{H}), 2.36(\mathrm{~s}, 6 \mathrm{H})$.

${ }^{13} \mathrm{C}$ NMR $\left(151 \mathrm{MHz}, \mathrm{CDCl}_{3}\right) \delta 167.37,162.95,143.20,137.86,137.63,135.16,134.73,131.29,130.43$, $129.36,128.05,126.16,124.16,123.16,20.43,19.95$.

LCMS (acidic method) $R_{t} 2.21 \mathrm{~min} \mathrm{~m} / \mathrm{z} 284.1[\mathrm{M}+\mathrm{H}]^{+}$.

\section{(4Z)-4-Benzylidene-2-(3,4-dimethylphenyl)oxazol-5-one (S1m)}

Prepared following General Method 1 with benzaldehyde $(59 \mu \mathrm{L}, 0.56 \mathrm{mmol})$ and 2-[(3,4dimethylphenyl)formamido]acetic acid $(120 \mathrm{mg}, 0.56 \mathrm{mmol})$. Product precipitated after quenching with water, and purified by Flash Silica Chromatography (0-10\% EtOAc:cyclohexane). Isolated as a yellow solid (44 mg, $0.16 \mathrm{mmol}, 28 \%$ ). 
${ }^{1} \mathrm{H}$ NMR $\left(600 \mathrm{MHz}, \mathrm{CDCl}_{3}\right) \delta 8.26-8.18(\mathrm{~m}, 2 \mathrm{H}), 8.00-7.88(\mathrm{~m}, 2 \mathrm{H}), 7.47(\mathrm{ddd}, J=15.9,8.1,4.2 \mathrm{~Hz}, 3 \mathrm{H})$, $7.28(\mathrm{~d}, J=7.7 \mathrm{~Hz}, 1 \mathrm{H}), 7.21(\mathrm{~s}, 1 \mathrm{H}), 2.36(\mathrm{~s}, 6 \mathrm{H})$.

${ }^{13} \mathrm{C}$ NMR $\left(151 \mathrm{MHz}, \mathrm{CDCl}_{3}\right) \delta$ 168.06, 163.98, 143.40, 137.67, 133.78, 133.63, 132.49, 131.15, 131.04, $130.43,129.43,129.04,126.24,123.13,20.43,19.92$.

LCMS (acidic method) $R_{t} 2.16 \mathrm{~min} \mathrm{~m} / \mathrm{z} 278.2[\mathrm{M}+\mathrm{H}]^{+}$.

\section{(4Z)-2-(3,4-Dimethylphenyl)-4-[(1-methylpyrazol-4-yl)methylene]oxazol-5-one (S1n)}

Prepared following General Method 1 with 1-methyl-1H-pyrazole-4-carboxaldehyde (61 mg, $0.56 \mathrm{mmol}$ ) and 2-[(3,4-dimethylphenyl)formamido]acetic acid $(120 \mathrm{mg}, 0.56 \mathrm{mmol})$. Product precipitated after quenching with water, no further purification. Isolated as a grey solid (73 mg, $0.26 \mathrm{mmol}, 47 \%$ ).

1H NMR (600 MHz, $\left.\mathrm{CDCl}_{3}\right) \delta 8.23(\mathrm{~s}, 1 \mathrm{H}), 8.05(\mathrm{~s}, 1 \mathrm{H}), 7.92-7.83(\mathrm{~m}, 2 \mathrm{H}), 7.26(\mathrm{~s}, 1 \mathrm{H}$, under solvent peak), $7.17(\mathrm{~s}, 1 \mathrm{H}), 4.01(\mathrm{~s}, 3 \mathrm{H}), 2.35(\mathrm{~s}, 6 \mathrm{H})$.

${ }^{13} \mathrm{C}$ NMR $\left(151 \mathrm{MHz}, \mathrm{CDCl}_{3}\right) \delta 167.57,162.18,142.85,142.74,137.58,133.80,131.11,130.38,129.09$, $125.86,123.37,122.94,117.16,39.55,20.37,19.94$.

LCMS (acidic method) $R_{t} 2.00 \mathrm{~min} \mathrm{~m} / \mathrm{z} 282.2[\mathrm{M}+\mathrm{H}]^{+}$.

\section{(4Z)-4-[(5-Methyl-3-furyl)methylene]-2-(p-tolyl)oxazol-5-one (S10)}

Prepared following General Method 1 with 5-methylfurfural (51 $\mu \mathrm{L}, 0.56 \mathrm{mmol})$ and 2-[(4-methylphenyl)formamido]acetic acid (110 $\mathrm{mg}, 0.56 \mathrm{mmol})$. Product precipitated after quenching with water, no further purification. Isolated as an orange solid (97 $\mathrm{mg}, 0.36 \mathrm{mmol}, 65 \%)$.

${ }^{1} \mathrm{H}$ NMR (600 MHz, CDCl $\left.{ }_{3}\right) \delta 8.03(\mathrm{~d}, J=8.1 \mathrm{~Hz}, 2 \mathrm{H}), 7.48(\mathrm{~s}, 1 \mathrm{H}), 7.31(\mathrm{~d}, J=8.1 \mathrm{~Hz}, 2 \mathrm{H}), 7.08(\mathrm{br} \mathrm{s}, 1 \mathrm{H})$, $6.29(\mathrm{~d}, J=3.0 \mathrm{~Hz}, 1 \mathrm{H}), 2.44(\mathrm{~s}, 6 \mathrm{H})$.

${ }^{13} \mathrm{C}$ NMR $\left(151 \mathrm{MHz}, \mathrm{CDCl}_{3}\right) \delta 167.71,162.51,158.07,149.49,144.07,129.81,129.11,128.27,123.08$, 122.22, 118.11, 111.07, 22.03, 14.41 .

LCMS (acidic method) $\mathrm{R}_{\mathrm{t}} 2.13 \mathrm{~min} \mathrm{~m} / \mathrm{z} 268.2[\mathrm{M}+\mathrm{H}]^{+}$. 
LCMS traces for $4 d, 4 f, 4 p$, and $4 y$

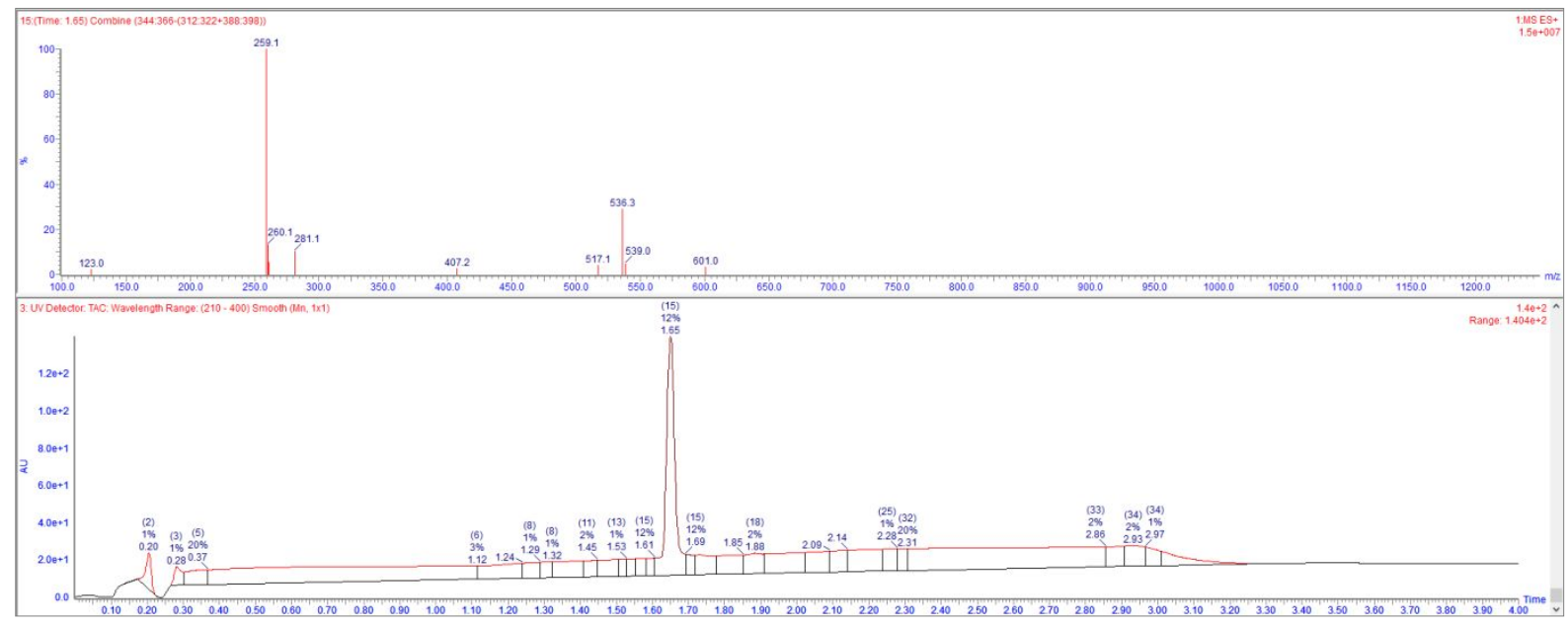

Figure S9. LCMS trace for $\mathbf{4 d .}$

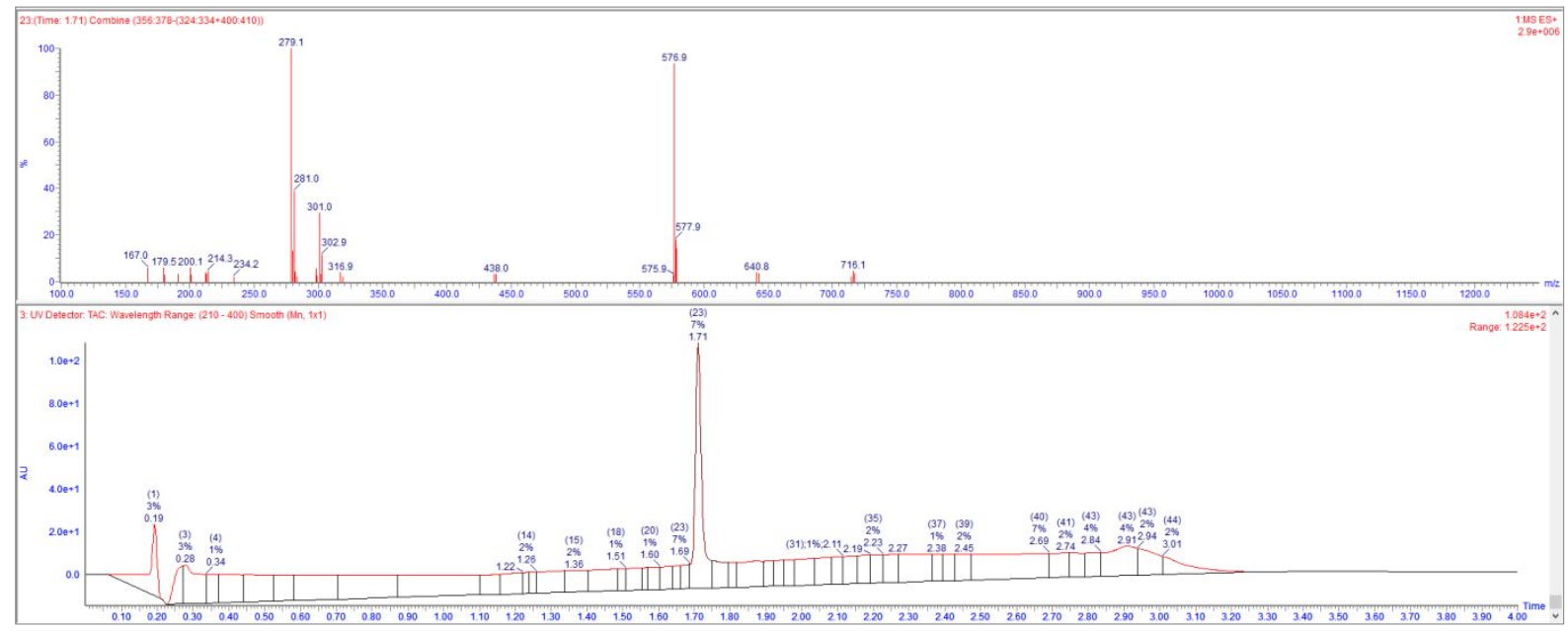

Figure S10. LCMS trace for $\mathbf{4 f}$. 


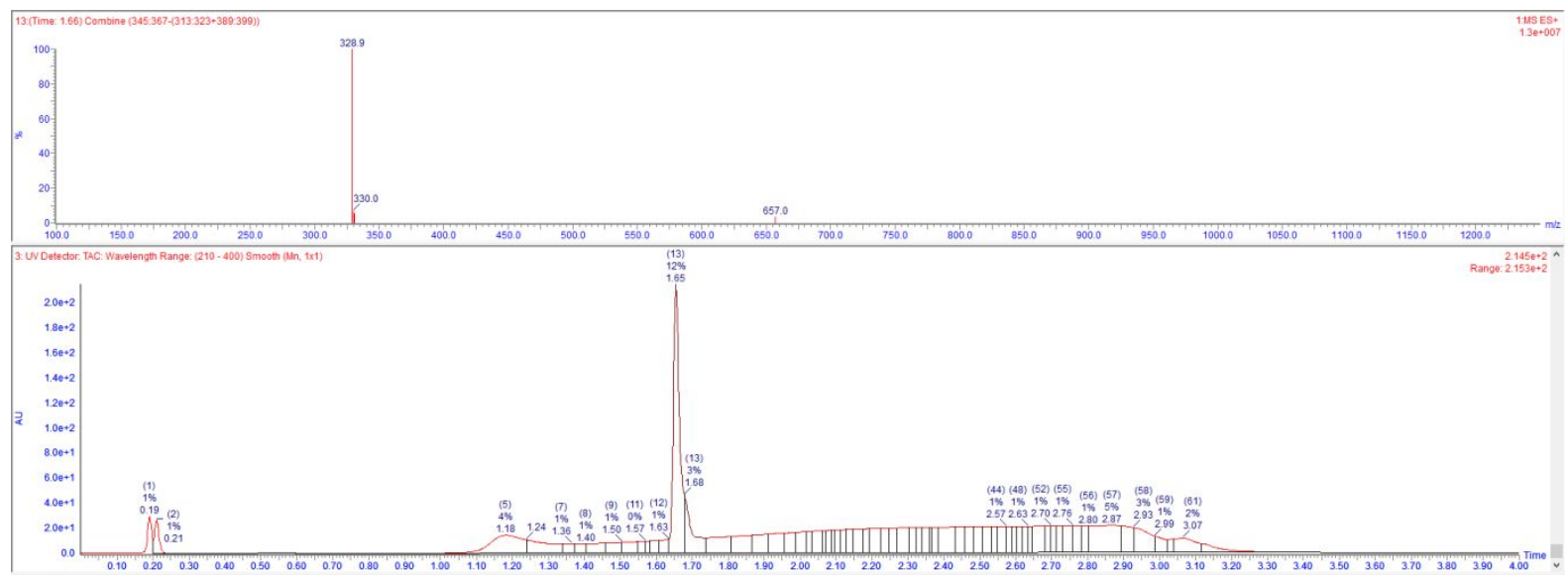

Figure S11. LCMS trace for $4 p$.

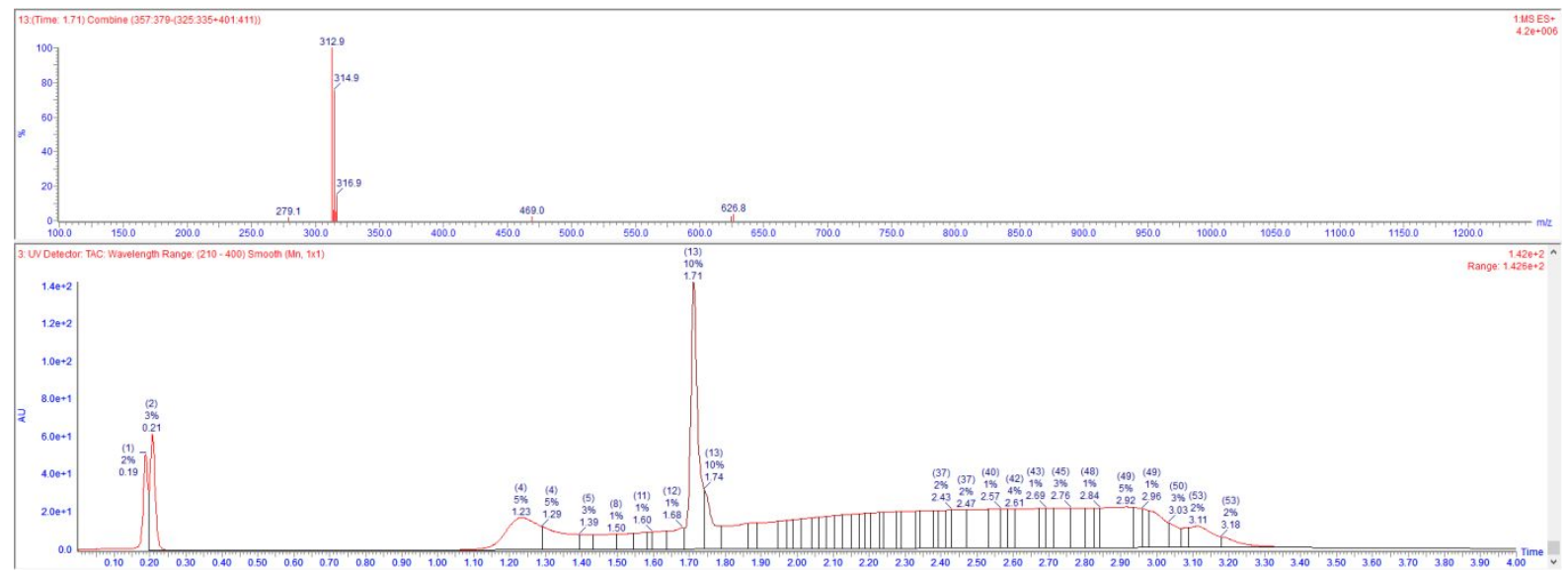

Figure S12. LCMS trace for $\mathbf{4 y}$. 
Notum OPTS and TCF/LEF screening data curves for $4 d$

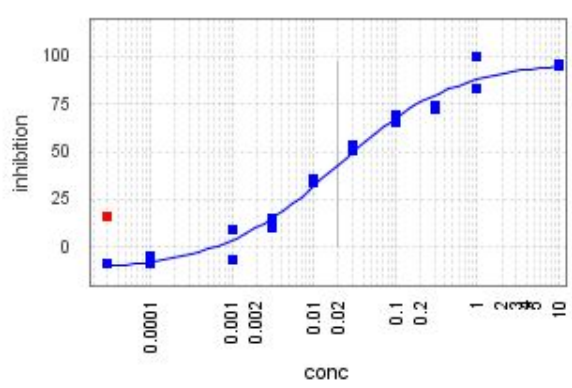

$\mathrm{IC}_{50} 19 \mathrm{nM}$

[Ref: 153107]

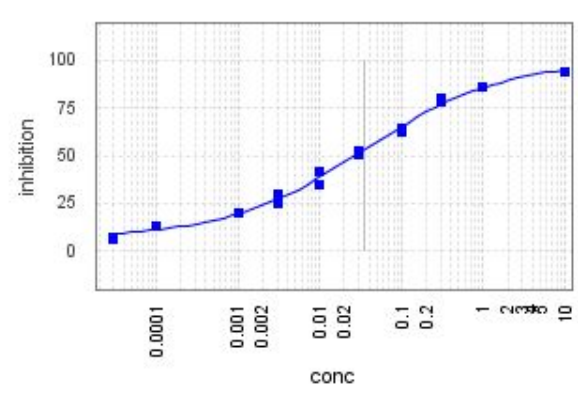

$\mathrm{IC}_{50} 36 \mathrm{nM}$

[Ref: 153168]

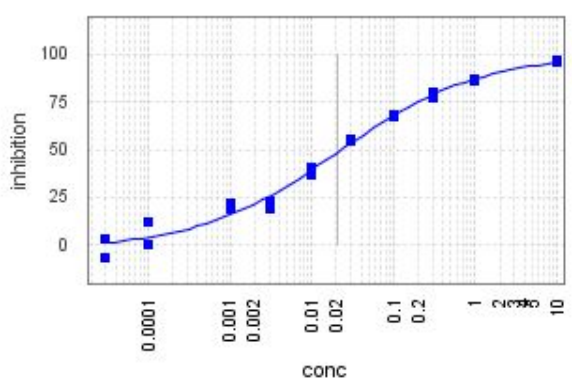

$\mathrm{IC}_{50} 21 \mathrm{nM}$

[Ref: 149815]

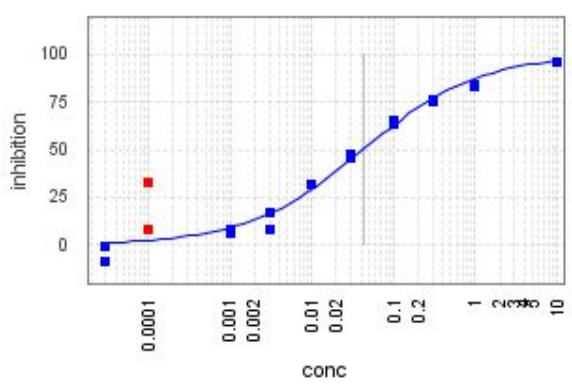

$\mathrm{IC}_{50} 43 \mathrm{nM}$

[Ref: 149792]

Figure S13. Notum OPTS data. Inhibition-concentration curves are representative medium examples for 4d (4 of 8 shown) from the larger data set for compounds 1-4. Examples are from different screening runs. 


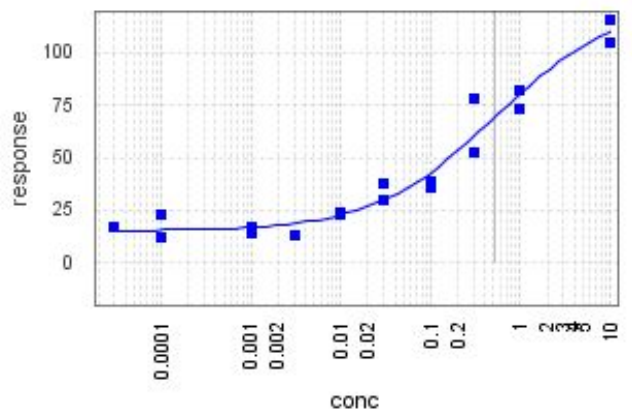

$\mathrm{EC}_{50} 510 \mathrm{nM}$

[Ref: 153748]

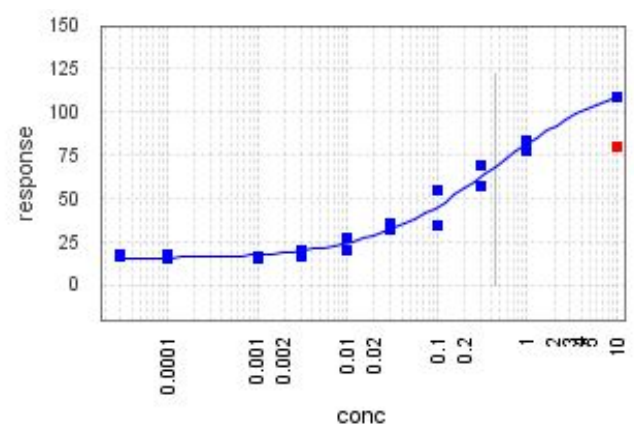

$\mathrm{EC}_{50} 440 \mathrm{nM}$

[Ref: 153817]

Figure S14. Notum TCF/LEF reporter (Luciferase) data with WNT3A (100 ng/mL). Response-concentration curves are for $\mathbf{4 d}$ from a larger data set for compounds 1-4. Examples are from different screening runs.

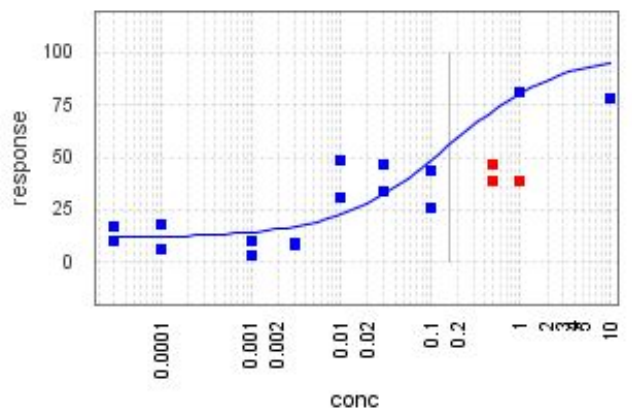

$\mathrm{EC}_{50} 160 \mathrm{nM}$

[Ref: 156588]

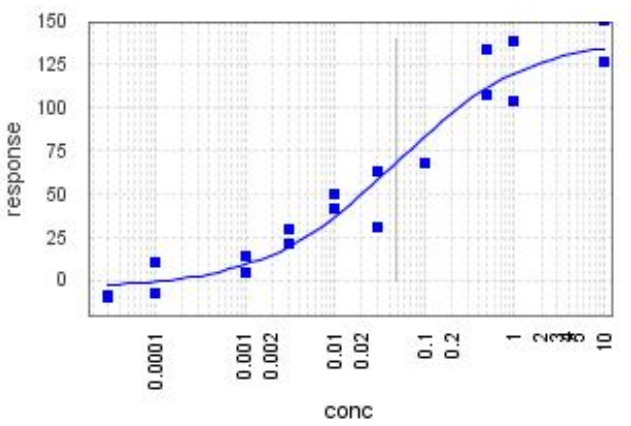

$\mathrm{EC}_{50} 47 \mathrm{nM}$

[Ref: 156649]

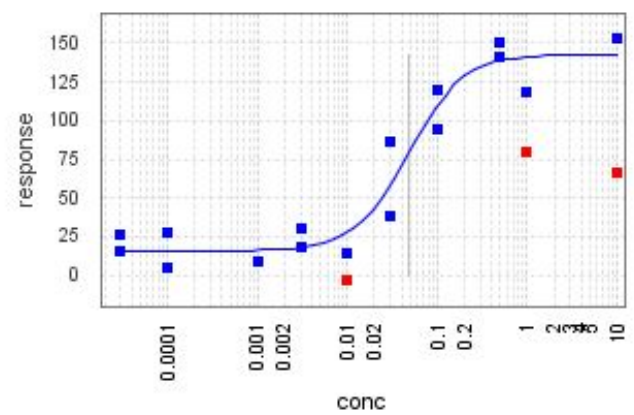

$\mathrm{EC}_{50} 48 \mathrm{nM}$

[Ref: 156629] 
Figure S15. Notum TCF/LEF reporter (Luciferase) data with WNT3A ( $200 \mathrm{ng} / \mathrm{mL}$ ). Response-concentration curves are for $\mathbf{4 d}$ from a larger data set for compounds $\mathbf{4 d}, \mathbf{4 f}, \mathbf{4 p}$ and $\mathbf{4 y}$. Examples are from different screening runs.

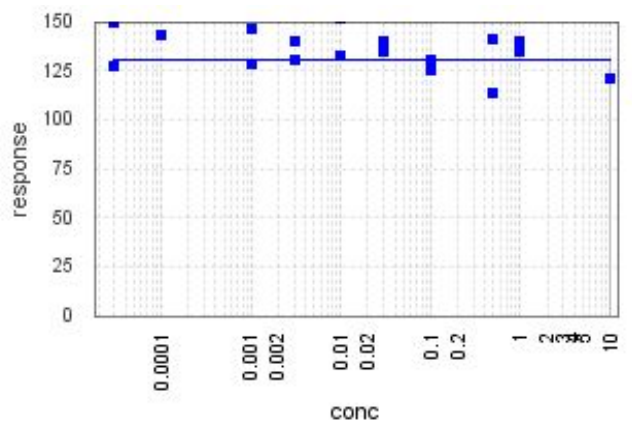

[Ref: 156589]

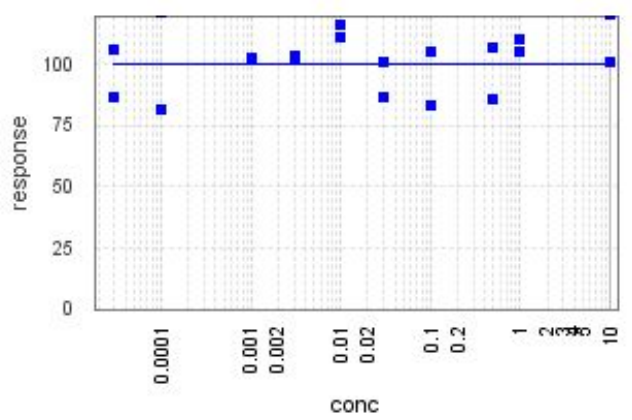

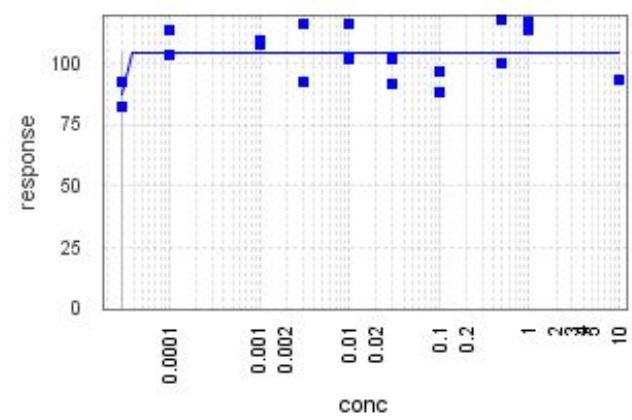

[Ref: 156628]

[Ref: 156648]

Figure S16. Notum TCF/LEF reporter (Luciferase) data with WNT3A $(200 \mathrm{ng} / \mathrm{mL}$ ) in the absence of Notum. Response-concentration curves are for $\mathbf{4 d}$ from a larger data set for compounds $\mathbf{4 d} \mathbf{d} \mathbf{4 f}$, $\mathbf{4 p}$ and $\mathbf{4 y .}$ Examples are from different screening runs.

Additional inhibition-concentration curves for compounds 1-4 will be made available upon reasonable request. 
